\title{
Language Learning Experiences and Learning Strategy Research: Voices of a Mainland Chinese Sfudent in Hong Kong
}

\author{
Xuesong (Andy) Gao \\ English Centre, The University of Hong Kong, Pokfulam, Hong Kong \\ English Department, Hong Kong Institute of Education, Taipo. \\ Hong Kong
}

The two-year longitudinal case study reported in this paper documents a Putonghuaspeaking mainland Chinese undergraduate student's language learning experiences and strategy use in an English-medium university in Hong Kong. Using a sociocultural approach, this paper focuses on three biographical episodes, which recount how the student attempted to create alternative ways of learning and seek new learning opportunities within the learning context, how she came to realise the limitations of her efforts and withdrew from her early active pursuits, and how she followed other mainland Chinese students in memorising words and attached her own meanings to her memorisation efforts. The paper highlights the social, cultural and political aspects of her strategy use and argues that learners' biographical experiences are an important avenue for us to understand learners' strategy use as a complicated phenomenon revealing the interplay between learners' agency and context.

doi: $10.2167 /$ illto11.0

Keywords: community of practice, learning experiences, learning strategy, sociocultural theory, longitudinal research

\section{Introduction}

Language learning strategy (LLS) research has received an enormous amount of attention in the last three decades since LLS research is expected to in form our pedagogic efforts to enhance learners' language learning capacity (e.g. Chamot, 2001, 2004; Ellis, 1994, 2004; Griffiths, 2004; McDonough, 1999; Oxford, 1989, 2003; Zhang, 2003). In recent years, the field has been challenged by its overdependence on the survey method, which often leads to decontextualised, ahistorical, correlational pictures of learners' strategy use in relation to other individual difference factors including motivation, beliefs and so on (e.g. Donato \& McCormick, 1994; Ellis, 1994, 2004; Gao, 2004; LoCastro, 1994; McDonough, 1999; Tseng et al., 2006). A more qualitative and context-sensitive research approach has been recommended to generate a contextualised understanding about learners' strategic learning efforts in specific contexts (e.g. Gan et al., 2004; Gao, 2004; Gu, 2003; He, 2002; Palfreyman, 2003; Parks \& Raymond, 2004). Such a methodological shift is particularly welcomed in light of the current 'social' turn in language learning research (e.g. Atkinson, 2002; Block, 2003; Sealey \& Carter, 2004; Watson-Gegeo, 2004; Zuengler \& Miller, 2006). 
The paper reports on the language learning experiences of one mainland Chinese undergraduate student in an English-medium university in Hong Kong, with an attempt to interpret her strategic leaming efforts from a sociocultural perspective (Donato \& McCormick, 1994; Gao, 2006; Thorne, 2005). In comparison with LLS research using other theoretical approaches, the strength of sociocultural LLS enquiries lies in using a holistic approach to explore why language learners adopt and display particular patterns of strategic efforts or behaviour in particular settings and broader learning contexts (Norton \& Toohey, 2001; Palfreyman, 2003; Parks \& Raymond, 2004; Toohey \& Norton, 2003). In the following sections, I will first situate my enquiry in the context of shifting language learning and LLS research paradigms. Following this, I will depict the context of the case study participant's language learning in Hong Kong and describe how I carried out a longitudinal ethnographic enquiry, from which the case study participant's experiential data were taken. Then I will take out three episodes from her experiential accounts to illustrate how the learning context facilitated and constrained her strategic language learning efforts or behaviour, which can be broadly classified as 'social strategy' and 'memorisation strategy' according to Oxford's (1990) taxonomy. The paper will end with some reflections on the study's implications for students pursuing tertiary education in the medium of English away from their home contexts like hundreds of mainland Chinese students abroad.

\section{Sociocultural Theory and LLS Research}

In recent years, language learning/teaching researchers have put increasing emphases on the sociocultural contexts of language learning in research (e.g. Atkinson, 2002; Block, 2003; Ellis, 1994; Sealey \& Carter, 2004; Watson-Gegeo, 2004; Zuengler \& Miller, 2006). 'Context' or 'real world situations' are considered 'fundamental, not ancillary, to learning', while in cognitive theories they are often treated as a variable modifying the internal acquisition process occurring in individual minds in previous research (Zuengler \& Miller, 2006: 37; and also Block, 2003; Norton \& Toohey, 2001; Sealey \& Carter, 2004; Thorne, 2005; Watson-Gegeo, 2004). Taking this sociocultural stance, researchers conceptualise language learning not only as metacognitive and cognitive activities in individual brains but also as social acts that are meaningfully related to learners' identity formation (Donato \& McCormick, 1994; Norton \& Toohey, 2001; Oxford, 2003; Palfreyman, 2003; Thorne, 2005; Watson-Gegeo, 2004). The notion of community of practice (Lave \& Wenger, 1991; also Wenger, 1998 ) is used to describe the language learning context in which language learners find themselves. Learning in the community of practice combines personal transformation with the evolution of social structures' through learners participating in those communities (Wenger, 2000: 227); it is also 'both a kind of action and a form of belonging' for learners (Wenger, 1998: 4; see also Lave \& Wenger, 1991).

As sociocultural learning theory conceptualises learners as social agents in active pursuit of linguistic competence and nonlinguistic outcomes, i.e. identity (e.g. Norton \& Toohey, 2001), language learners' strategy use is not only seen as 
a cognitive choice made by individuals but also considered an emergent phenomenon directly connected to the practices of particular cultural groups or communities of practice that learners belong to (Donato \& McCormick, 1994; Gao, 2006; Gillette, 1994; He, 2002; Lave \& Wenger, 1991; Norton \& Toohey, 2001; Palfreyman, 2003; Toohey \& Norton, 2003; Wenger, 1998). Whereas the bulk of learning strategy research is associated with learners' metacognitive and cognitive strategy use, in sociocultural studies, learners' strategic efforts not only facilitate cognitive and metacognitive learning processes (Cohen, 1998) but also subvert the imposing learning context to 'open up access within power structures and cultural alternatives for learners' (Oxford, 2003; 79). Such theorisation of learning strategy needs to be treated with caution when appreciating how much impact an individual learner's human agency, their self-consciousness, reflexivity, intentionality, cognition, emotionality and so on (e.g. Giddens, 1984; Sealey \& Carter, 2004) has on the existing structural realities in a learning context, which are often enduring, anterior to his or her entry to the context, and autonomous from his or her actions or discursive construction (Layder, 1990, 1993; Sealey \& Carter, 2004). Language learners' strategic efforts, revealing what they can contribute to their own language learning (Chamot, 2001), are also profoundly constrained and/or facilitated by contextual realities, including material conditions, sociocultural discourses and social networks as well as social alignments and arrangements of the aforementioned contextual elements and their underlying social relations (e.g. He, 2002; Joseph, 2006; Layder, 1990; Norton \& Toohey, 2001; Oxford, 2003; Palfreyman, 2003, 2006; Sealey \& Carter, 2004; Toohey \& Norton, 2003). This perspective on learners' strategy use does not endorse a voluntarist view that the existence of contextual realities hinge upon individuals' interpretative construction and the role of human agency prevails upon the impact of contextual realities. It also rejects a structuralist position in social sciences that individuals' behaviour is determined by contextual realities and human agency has little impact on contextual realities (for an overview, see Sealey \& Carter, 2004). In other words, language learners' strategy use is often a constrained choice, but nevertheless a choice made by language learners. This means that agency, as an endowed human quality, is a prerequisite to making choices in strategy use for language learners. This also means that language learners adopt particular learning strategies within a learning space constrained/facilitated by contextual realities. For this reason, before presenting the case study informant's experiential accounts to illustrate the continuous interplay between learner agency and contextual realities underlying her strategy use, I shall proceed to give a description of the learning context in Hong Kong and the case study participant's institutional setting.

\section{The Context and the Institutional Setting}

Although learning contexts on the Chinese mainland and in Hong Kong are similar on many counts, Hong Kong remains a linguistically complex context for many, on which there is no dearth of research (e.g. Benson, 1997; Bolton \& Lim, 2000; Boyle, 1997; Davison \& Lai, 2007; Evans, 2000; Keung, 2006; Lai, 
2001; Morrison \& Lui, 2000). A simplistic portrayal of Hong Kong's linguistic landscape includes Cantonese, a local version of Chinese as the dominant language in daily life and most social, cultural and political occasions although Hong Kong was once a British colony and English is one of its official languages. The English language is widely used in the professional sectors and constantly promoted as an important asset for individuals' career and social development as well as a crucial means for Hong Kong to retain its international image. The status of Putonghua has been undergoing changes after the handover in 1997 (e.g. Davison \& Lai, 2007; Keung, 2006). Especially in recent years, when mainland Chinese travellers are more visible in Hong Kong and contribute to Hong Kong's reviving economy, the local community has started attaching greater importance to Putonghua.

The university concerned in the enquiry, namely the University of Hong Kong, has been one of the leading English-medium universities in the region and also one of the most prestigious universities in Hong Kong. Having said this, Cantonese is the most dominant language on the campus, in student halls, student group discussions and social functions. Only in recent years have tertiary institutions in Hong Kong started accepting students from the Chinese mainland in large numbers; and the University of Hong Kong has already become one of the most popular choices among mainland Chinese students. In 2006, over 10,230 applicants reportedly applied for 270 undergraduate places allocated to mainland Chinese applicants by the university (Mingpao, 2006a). The majority of these students are eligible for top universities on the Chinese mainland. Only a small minority of mainland Chinese students are able to speak Cantonese. The rest of them, depending on their provinces of origin, speak various dialects and share Putonghua as the common dialect. They, together with other non-local students, may often be in danger of being excluded from local students' community because of the language barrier. The situation is further complicated by the fact that the English-medium university requires a high level of English proficiency among their applicants, while most of the mainland Chinese students, when making decisions about their tertiary studies in Hong Kong, intend to use Hong Kong universities' English-medium instructional environment as a means to acquire better English competence (e.g. Mingpao, 2006b). The prevalent use of Cantonese inevitably makes it difficult for those who want to improve their English to achieve their English learning objectives.

The problems that mainland Chinese students experienced in Hong Kong as documented in the data collection process also challenge a homogenous notion of Chinese learners (e.g. Clark \& Gieve, 2006; Gieve \& Clark, 2005; Kumaravadivelu, 2003; Stephens, 1997). Although mainland Chinese students share the same ethnic and cultural background as the local Chinese population in Hong Kong, they have remarkably different historical, political and social experiences. Hong Kong had been a British colony for over 150 years before the handover in 1997. When mainland China was still in a state of political turmoil, Hong Kong had already achieved an enviable economic success in the region. As unfamiliar siblings to local students, mainland Chinese students face the vestiges of an 'othering' process, in which mainland Chinese are often portrayed as uncivilised and crude in contrast to modern cosmopolitan Hong 
Kong people largely based on these differences in the two peoples' experiences (Ho et al., 2003; Li et al., 1995; Ma \& Fung, 1999; Schack \& Schack, 2005). The social attitudes towards mainland Chinese may be changing due to the recent boom of tourists from the Chinese mainland in Hong Kong. The process to differentiate 'us-them' may be initiated on the part of mainland Chinese in their encounters of local population in Hong Kong, too. However, it is fair to say that these differences often constitute a social wall between two people sharing the same ethnic origin (e.g. Ho et al., 2003).

\section{The Study}

All the biographical data used in the paper were taken from a two-year-long longitudinal study on a group of mainland Chinese students in Hong Kong. The study is divided into three stages. In the first stage, I interviewed 22 mainland Chinese students about their language learning experiences on the Chinese mainland. In the second stage, I followed six students, using a variety of means to collect data, including regular conversations, strategy checklist, observation, field notes and email correspondence. In the third stage, 15 out of the 22 participants who were interviewed two years ago were interviewed for the second time about their language learning experiences in Hong Kong.

This paper focuses on one of the longitudinal case study participants, given the pseudonym of April, and the experiential data collected through regular conversations in the second research stage. April was a mainland Chinese student who came to pursue undergraduate studies as an Economics and Finance student. An early interview about her language learning experiences on the Chinese mainland confirmed that she was a top student in her secondary school and saw English competence as an essential component of her personal identity and a crucial asset to claim respect from other people. This explains why she always appeared to be highly motivated in learning English, in comparison with other case study participants in the longitudinal inquiry.

To analyse a massive amount of data related to April, I adopted a synthetic approach (Colley \& Diment, 2001), in which I constantly read through all the conversation summaries and other data to have a global understanding of what actually happened to April during the two years. Such reading started when the data collection began and subsequently informed the topics of our regular conversations, through which some of my initial findings were checked and confirmed by her. Through a constant process of reading and checking, an overview of her experiential accounts took shape and gradually started having a plot or the development of some major themes, which enabled me to impose some structure in the account contained in this paper after the plot was verified by the participant herself. Drawing on such a collaborative research process, the structured account in the paper intends to answer the question of how the informant's strategy use, which is indicative of her agency in language learning, was both constrained and engendered by linguistic and social complexities in the learning context. All the quotes in the paper were English in the original. 


\section{Biographical Episodes}

The informant's two years' language learning experiences in Hong Kong were intertwined with her persistent search for more learning opportunities and regular setbacks frustrating her strategic moves. She had apparently managed her socialisation with local students quite well, which helped create a facilitative learning environment for her English and Cantonese learning. At the same time, a gradual process of psychological distancing from local students can also be seen in her experiential accounts, as she progressively moved closer to the mainland Chinese students and was socialised into different patterns of strategy use. The selected biographical episodes are intended to illustrate these contradictory processes and reveal the interplay between the informant's agency and the context underlying these processes and changes in her strategy use.

\section{Episode 1: Whenever they could speak Cantonese, they would speak Cantonese!}

The data indicate that April, like other participants in the study, believed that the university provided a better language learning environment than institutions on the Chinese mainland. As a result, her strategy use in learning English was greatly facilitated by the new environment. The university attracts more international students and local students with high English proficiency than other local universities in Hong Kong. It also recruits high-calibre mainland Chinese students whose English is likely to be more proficient than their counterparts on the Chinese mainland. In other words, there were many material resources and proficient English users (social resources) available to support April's English language learning. Our regular conversation summaries show that, starting from her arrival in Hong Kong, April had been actively using these resources to improve her English as well as her Cantonese. In the case of learning English, the comparison of two strategy use checklists completed by her in the first and second semesters reveals that she progressively adopted a greater variety of strategic behaviour to increase her exposure to English and to use English in Hong Kong. In her first semester at the university, she regularly listened to English radio or watched English TV programmes; she also established an English-speaking partnership with another mainland Chinese student; she tried to implement a rule to ensure that she would use English for all academic matters including discussions and tutorials, where students easily lapsed into Cantonese and even Putonghua. Apart from these strategic moves, she invested her time and energy in making friends and socialising with local students at her hall and in her faculty, which contributed to her expanded access to local students' groups and Cantonese competence and her increased social opportunities for using English. Far more importantly, it gave her a sense of belonging in the student community. In the following interview extract, she describes how she started a language exchange partnership with a local student which evolved into a scheme involving three languages. 
Extract 1:

One day, I got a message from an Arts student, a girl. She said that she was interested in learning Putonghua. She asked me whether I was interested in language exchange with her. At that time, my Cantonese was poor. So I agreed. For the first time meeting, both of us talked in Putonghua because I could not express myself in Cantonese. Last night, both of us were speaking in Cantonese (laughter). Do you think it funny? Hong Kong people could not change their human nature. Whenever they could speak Cantonese, they would speak Cantonese. Because her Putonghua was not too good, sometimes she would use a lot of English to explain herself. Once she started speaking English to me, I would switch to English. But when she switched back to Putonghua, I would try to speak in Cantonese. If I failed in my attempt, I would use Putonghua. It was just like that. In the beginning, I would ask her about basic terms in Cantonese. In the middle, we spoke more English because she found my English was good. So she was interested in practising English with me. In the end, both of us switched to Cantonese. I think that it is funny. They could not change their human nature of speaking Cantonese. (3 September 2004)

The episode sheds light on April's readiness to create alternative ways of learning and embrace possible language learning opportunities arising from her exchanges with local students. It also reveals the linguistic complexity that April had to cope with to maximise the development of her Cantonese and English competence. As she skilfully manoeuvred the language exchange scheme to benefit her Cantonese and English learning, she also had to avoid a common phenomenon shared by many mainland Chinese students, that is, their opportunities to use English significantly decreased when they were identified as able speakers of Cantonese. Therefore, it became a strategic move for April to use the evolving relationships among three languages (Cantonese, English and Putonghua) in the wider social context for her own benefit. Such strategic efforts revealed her agency in taking control of her own language learning and participating in the local students' community (Norton \& Toohey, 2001), but the impact of linguistic complexity in the learning context is also manifest in her account.

\section{Episode 2: Making friends with individuals does not make me accepted by the community}

In spite of April's active strategy use to carve out a favourable niche for her language learning, the complicated learning context constrained her strategy use in acquiring linguistic competence and striving for her acceptance in the learning community. Although the early conversation summaries indicate that her integration into the students' community was quite successful, the data also recorded a process of alienation from local students in her experiences, in which she felt that the differences she had with local students gradually became more, not less, apparent in ongoing social exchanges. Consequently, she also felt that she was prevented from participating fully in student community life. 
It is characteristic of many highly motivated mainland Chinese students in Hong Kong that they are always anxious to prove themselves competent members of the community. One way for them to achieve this is, in addition to having good academic results, to participate in numerous student competitions. In two years, April made a few unsuccessful attempts to participate in student competitions. The particular student competition in this episode, a student proposal competition, which took place three months after her arrival, also functioned as an incentive for her to practise English intensively as the competition was organised by a local branch of an international student organisation. However, according to April, on the first-round proposal-making day, she disappointedly found that Cantonese was the dominant language in spite of the international profile claimed by the competition organisers because most participants were local students. The competition process gave rise to the first significant clash recorded in the data between April's sociocultural background and the local students. The competition required all the participants to work in a group and discuss the assigned reading materials for making proposals. April intended to make a proposal that somehow linked the Chinese mainland and Hong. Kong but local participants were more interested in proposing topics like corporate responsibility, to which she attached little significance. In the end, when the group voted for the proposal to be adopted, her proposal was turned down; it only obtained three votes from mainland Chinese participants, including herself, and no local participants supported her proposal. This result was certainly disappointing for April but the implications were even more serious. The rejection, along with daily experiences of 'us -other' differentiation in the media and social exchanges (Ho et al., 2003; Li et al., 1995; Ma \& Fung, 1999; Schack \& Schack, 2005) made her suspect that her proposal was not treated fairly because it was about the Chinese mainland.

Extract 2:

I would like to talk about mainland [...]. It created problems for me because sometimes I had to be judged by a group of local students. They would think you odd, very odd, talk differently. When their culture and values are not there, they think that you are not one of them. [...] Maybe, we have different concerns and cultural values. I feel that I am not one of them. Maybe in the very beginning, I felt that I was lucky that I am not one of them because I have different opinions. I think that I may help to change, well, show them that there are different ways of thinking. But now I feel that I could not no matter how hard I tried because it was too difficult. (15 November 2004)

This incident, together with others, left April with the impression that she could speak but was constantly not heard in the student community. It was from such socialisation experiences that she discovered the insurmountable wall between her and the community and the difficulty in securing a role in the local community. She realised that there were more than linguistic barriers for her to overcome in Hong Kong; the cultural gap also prevented her from becoming a fully participatory member in the students' community regardless of her shared cultural heritage and ethnic background with local students. 
After the competition, she did not give up her use of social strategies with local students to improve her English and Cantonese entirely. However, the data do show that the incident had a negative impact on her sense of belonging to the community and use of social strategies in language learning. In previous conversations, she had already complained that her insistence on using English alone put her at risk of being distanced by other Putonghua-speaking mainland Chinese students, leading to occasional feelings of isolation. After this incident, she mentioned more frequently her mainland Chinese friends in her conversations and eventually after six months in Hong Kong, she found herself using more Putonghua and less Cantonese and English.

Extract 3:

I speak more and more Putonghua now. Now some people approached, Hong Kong people, I will say Putonghua to them sometimes. I will not say Cantonese to them. I do not know why. Even my professor handed me handout, I will say 'xiexie' even though I know how to speak Cantonese. (9 March 2005)

As she started appreciating the fact that she shared more with other mainland Chinese students, her strategy use in learning English began to display more influences from her mainland Chinese peers.

\section{Episode 3: I need my own voice in learning!}

Although her unsatisfactory participation experiences in the local students' communities discouraged her active use of social learning strategies, the data reveal that April attempted to regain momentum in learning English by expanding her vocabulary after she found herself using more Putonghua and less English. As she spent more time interacting with her mainland Chinese peers, she also found that she was exposed to a popular discourse among them, which views achieving high academic results, receiving a doctoral scholarship from an American university or getting a job offer from a prestigious company in Hong Kong as the pinnacle of success for a mainland Chinese student at the university. She saw that many of her mainland Chinese friends were motivated by such visions by making strenuous efforts to memorise words in the Graduate Record Exam (GRE) vocabulary list. This was widely regarded as an important part of the preparation for the GRE exam among those who wished to apply for graduate studies in North American universities. She also noted that many other mainland Chinese students felt compelled to do so without actually believing in its long-term impact on their acquisition of linguistic competence. Yet they tried to memorise three sub-lists of new words in the vocabulary list and review all the sub-lists they had memorised early every day until they had reviewed the same word seven times. The most popular vocabulary book had 51 sub-lists ( 6000 words in total) and in theory took 17 days of concentrated effort to memorise. This was obviously a daunting learning task. Nevertheless, even though April herself once detested rote memorisation and systematic reviewing of vocabulary, she found it necessary to spend a great deal of time memorising and reviewing the GRE wordlists to acquire more vocabulary and she modified the popular memorisation approach to suit her needs. 
Extract 4:

I could not do it myself. It was terrible. But I decided to review two lists a week, after a semester, I can finish forty lists. From the beginning of the semester, I have completed 8 lists. It is not that bad. The problem is whether I will persist. I think that my way is much better. Because in the 17-days way, people just look at or stare at the words, they do not know how to read, they do not know how to use. They do not care. (21 September 2005)

While her decision to memorise GRE wordlists was influenced by her mainland Chinese peers, the data suggest that she understood the importance of having a large vocabulary and was aware of the necessity of providing her own reasons for this memorisation effort. Otherwise, she felt that it was extremely difficult for her to continue memorising words (in Extract 4). However, she could not find meanings and discourses that could motivate her learning efforts among her mainland Chinese peers. The popular reasons among other mainland Chinese students at the university for spending time memorising words were associated with the uncertainties that they began to foresee upon graduation. Although many of them initially intended to seek employment in Hong Kong, they began to seriously consider preparing for undertaking postgraduate studies elsewhere - plan B - as the linguistic and sociocultural differences they had with local students added to their insecurity and uncertainty as non-local residents in Hong Kong. In addition, there were some mainland Chinese students who regarded Hong Kong's Englishmedium tertiary education as a stepping stone for them to pursue postgraduate studies in countries like the USA and Great Britain. Although she probably shared some of these motives, she did not find the image of successful students in the dominant discourse of success among her mainland peers inspiring and wanted to have her own voice in learning English. In other words, she sought to be different and to take an alternative path.

Extract 5:

There is always a voice inside me, telling me to come back to China. But after I came to Hong Kong, everybody is talking about going abroad, going overseas, PhD, finding a good job, staying in Hong Kong, making a lot of money. My own voice is becoming less and less audible. I cannot say it. I need to have my own voice. [...] Now because I found studying English, if you have some good knowledge of English, it really means something, [...] if I have a good knowledge of English, if I go back, it is OK just for me to be an English teacher, it does not matter. [...] Even if I do not have to be a PhD, I can still help other people. (21 September 2005)

In a series of conversations, she recounted how she found new meanings in learning English after becoming a fan of a nationwide Super Girl competition winner in the summer of 2005. The Super Girl competition is like a Chinese version of American Idol except that all the contestants are female (Jacks, 2005; Keane, 2006). The winner in 2005 was a peculiar cultural icon elected by millions of young Chinese through text-messaging, who possesses 'attitude, originality and a proud androgyny that defied Chinese norms' (Jacks, 2005). 
The message mediated through this cultural icon to her as well as thousands of fans was clear, that is, it is wonderful to be different.

Extract 6:

Maybe in the bottom of my heart, I feel that I was a little bit like Li Yu Chun, when I was in high school. If I did something like her, it would be perfect. If I was a Li Yu Chun, [...] I will not do what I am doing now. I am not dreaming a star life. Now she is a superstar. But before that, she was just a common girl like everybody. A common girl. But I did not choose to be like her. I focused on my academic studies instead. (21 September 2005)

As April found that her idol could not pronounce English words properly in the contest, she decided to write a letter telling her how to pronounce them properly. In return, she received a photo with her idol's signature. An apparently insignificant incident empowered her with her own voice in learning English as she became aware that her English competence could be truly meaningful to her even if she returned to the Chinese mainland. As a result, she realised that learning English could have many other meanings and she did not have to define its meaning as something like receiving a good job offer in Hong Kong or doing doctoral studies in the USA, as did many mainland Chinese students.

Such reflections gave her a sense of ownership in her language learning, which made memorisation efforts much more pleasant and enjoyable for her. The whole episode showed that April, as a social agent, could reflexively and purposefully transform a series of strenuous efforts into something meaningful to pursue her idealised life and social relationships, by drawing inspiration from her own life experiences. However, this does not negate the fact that April adopted memorisation strategies because she was almost obliged to do so by peers from her social group and the situation she found herself in after discovering the enduring gap between local students and herself. Thus, regardless of her discursive construction, her strategy use was a product of the interplay between her agency and contextual realities, both having influenced her language learning and strategy use.

\section{Conclusions}

This paper has documented three episodes from April's biographical experiences and demonstrated the interplay between her agency and contextual realities in her strategy use. While April was an active social agent trying to use various material and social resources to create a better learning environment and ensure her learning achievements, her strategy use was both facilitated and constrained by the contextual realities, which are anterior to her language learning and relatively enduring regardless of the informant's efforts to create a supportive learning space (Layder, 1990; Sealey \& Carter, 2004). A case study is obviously limited in its capacity for generalisation, but it has demonstrated that learners" biographical experiences could be an important avenue for us to understand learners' strategy use as a complicated 
phenomenon revealing the interplay between learners' agency and context. An understanding of the interplay of context (structure) and agency in learners' strategic efforts will help us appreciate the complexity of learners' strategy use and inform language teachers' efforts to develop learners' capacity to control their learning as thousands of students moved across borders. These students, unlike immigrants, during the limited time of their academic tours abroad, may not be well integrated into their receiving communities. Many of them may not even have the wish to be members of their host communities. For these students, our development efforts should not be limited to their metacognitive knowledge or self-regulatory capacity (e.g. Palfreyman, 2003). To empower them, we should also foster their cultural and micropolitical literacy, which will help them identify the powerful relationships among different social groups in the host communities and utilise these relationships to create a more facilitative language learning space for their strategy use and linguistic growth (Norton \& Toohey, 2001; Palfreyman, 2003). Far more importantly, our efforts should also aim at strengthening their capacity to cope with ongoing differences between them and their hosts rather than focusing on how to integrate them as full members into their host commurities, which seems to be more realistic. Such development efforts may start with a critical analysis of the 'us-them' discourses or other awareness-raising activities. Because it often takes a long time and many important life experiences for these messages to be internalised by learners, it will benefit learners if they can be exposed to strategic, cultural and micropolitical literacy development efforts much earlier than their actual entry to their host communities. Alternatively, it requires a substantial amount of resources to provide ongoing consultation and support to learners who feel motivated to acquire linguistic competence but frustrated by the contextual realities.

\section{Acknowledgements}

I wish to express my gratitude to anonymous reviewers, Dr Chris Davison at the University of Hong Kong, Dr Phil Benson at Hong Kong Institute of Education and the case study participant for their support in the research and writing process. The study was partially funded by Sik Sik Yuen Educational Research Fund, at the Faculty of Education, the University of Hong Kong.

\section{Correspondence}

Any correspondence should be directed to Xuesong Gao, English Centre, Hong Kong University, Pokfulam, Hong Kong (Xuesong.Gao@hkusua. hku.hk, andygohteacher@hotmail.com).

\section{References}

Atkinson, D. (2002) Toward a socjocognitive approach to second language acquisition. The Modern Language Journal 86, 525-545.

Benson, P. (1997) Language rights and the medium of instruction policy in Hong Kong. Hong Kong Journal of Applied Linguistics 2 (2), 1-21.

Block, D. (2003) The Social Tum in Second Language Acquisition. Edinburgh: Edinburgh University Press. 
Bolton, K. and Lim, S. (2000) Afterword: Futures for Hong Kong's English. World. Englishes 19 (3), 429-443.

Boyle, J. (1997) Imperialism and the English language in Hong Kong. Journal of Multicultural and Multilingual Development 18, 169-181.

Chamot, A.U. (2001) The role of learning strategies in second language acquisition. In M.P. Breen (ed.) Learner Contributions to Language Learning: New Directions in Research (pp. 25-43). Harlow: Longman.

Chamot, A.U. (2004) Issues in language learning strategy research and teaching. Electronic Journal of Foreign Language Teaching 1 (1), 14-26.

Clark, R. and Gieve, S.N. (2006) On the discursive construction of the Chinese learners. Language, Culture, and Curriculum 19 (1), 54-73.

Cohen, A.D. (1998) Strategies in Learning and Using a Second Language. Harlow: Longman.

Colley, H. and Diment, K. (2001) Holistic research for holistic practice: Making sense of qualitative research data. A paper submitted for the Learning and Skills Research Network Annual Conference, Cambridge, UK, December.

Davison, C. and Lai, W. (2007) Competing identities, common issues: Teaching in Putonghua. Language Policy 6 (1), 119-134.

Donato, R. and McCormick, D. (1994) A sociocultural perspective on language learning strategies: the role of mediation. The Modern Language Journal 78, 453-464.

Ellis, R. (1994) Study of Second Language Acquisition. Oxford: Oxford University Press.

Ellis, R. (2004) Individual differences in second language learning. In A. Davies and C. Elder (eds) The Handbook of Applied Linguistics (pp. 525-550). Oxford: Blackwell Publishing.

Evans, S. (2000) Hong Kong's new English language policy in education. World Englishes 19, 185-204.

Gan, Z., Humphreys, G. and Hamp-Lyons, L. (2004) Understanding successful and unsuccessful EFL students in Chinese universities. The Modern Language Journal 88 (2), 229-244.

Gao, X. (2004) A critical review of questionnaire use in learner strategy research. Prospect: An Australian Journal of TESOL 19 (3), 3-14.

Gao, X. (2006) Understanding changes in Chinese students' uses of learning strategies in China and Britain: A socio-cultural re-interpretation. System 34 (1), 55-67.

Giddens, A. (1984) The Constitution of Society: Outline of the Theory of Structuration. Berkeley: University of California Press.

Gieve, S.N. and Clark, R. (2005) 'The Chinese approach to learning': Cultural trait or situated response? The case of a self-directed learning programme. System 33 (2), $261-276$.

Gillette, B. (1994) The role of learner goals in L2 success. In J.P. Lantolf and G. Appel (eds) Vygotskian Approaches to Second Language Research (pp. 195-214). Norwood, NJ: Ablex.

Griffiths, C. (2004) Language learning strategies: theory and research. Occasional Paper No.1. School of Foundations Studies, AIS St Helens, Auckland, New Zealand.

Gu, Y. (2003) Fine brush and freehand: The vocabulary-learning art of two successful EFL learners. TESOL Quarterly 37 (1), 73-104.

$\mathrm{He}$, A. (2002) Learning English in different linguistic and socio-cultural contexts. Hong Kong Journal of Applied Linguistics 7 (2), 107-121.

Ho, D.Y.F., Chau, A.W.L., Chiu, C. and Peng, S.Q. (2003) Ideological orientation and political transition in Hong Kong: Confidence in the future. Political Psychology 24 (2), 403-413.

Jacks, S. (2005) Li Yu Chun loved for being herself. Time (International Edition) 166 (15), 56.

Joseph, J.E. (2006) Applied linguistics and the choices people make (or do they?). International Journal of Applied Linguistics 16 (2), 237-241.

Keane, M. (2006) From made in China to created in China. International Journal of Cultural Studies 9 (3), 285-296. 
Keung, M.L. (2006) Expressing cultural identities: University students' attitudes towards the use of Putonghua in Hong Kong. Unpublished PhD thesis, University of Leicester, UK.

Kumaravadivelu, B. (2003) Problematizing cultural stereotypes in TESOL. TESOL Quarterly 37 (4), 709-719.

Lai, M. (2001) Hong Kong students' attitudes towards Cantonese, Putonghua, and English after the change of sovereignty. Journal of Multicultural and Multilingual Development 22, 112-133.

Lave, J. and Wenger, E. (1991) Situated Learning: Legitimate Peripheral Participation. New York: Cambridge University Press.

Layder, D. (1990) The Realist Image in Social Science. Basingstoke: Macmillan Press.

Layder, D. (1993) New Strategies in Social Research: An Introduction and Guide. Cambridge: Polity Press.

Li, F.L.N., Jowett, A.J., Findlay, A.M. and Skeldon, R.S. (1995) Discourse on immigration and ethnic identity: Interviews with professionals in Hong Kong. Transactions of the Institute of British Geographers 20 (3), 342-256.

LoCastro, V. (1994) Learning strategies and learning environments. TESOL Quarterly $28(2), 409-414$.

Ma, E.K.W. and Fung, A.Y.H. (1999) Re-sinicization, nationalism and the Hong Kong identity. In S. Clement and J.Chan (eds) Press and Politics in Hong Kong: Case studies from 1967 to 1997 (pp. 497-528). Hong Kong: Chinese University Press.

McDonough, S.H. (1999) Learner strategies. Language Teaching 32, 1-18.

Ming Pao on Saturday (2006a) Mainland applicants to Hong Kong's universities increase dramatically. http: / / life.mingpao.com $/ \mathrm{cfm} /$ dailynews 3 b.cfm?File $=20060617 /$ nalgf/gfal.txt. Accessed 28.09.07.

Ming Pao on Tuesday (2006b) Editorial. http://life.mingpao.com/cfm/dailynews3b. cfm?File $=20060725 /$ nalmr $/$ mrb.txt. Accessed 28.09.07.

Morrison, K. and Lui, I. (2000) Ideology, linguistic capital, and meditum of instruction in Hong Kong. Joumal of Multicultural and Multilingual Development 21, 471-486.

Norton, B. and Toohey, K. (2001) Changing perspectives on good language learners. TESOL Quarterly 35, 307-321.

Oxford, R. (1989) Use of language learning strategies: A synthesis of studies with implications for strategy training. System 17, 235-247.

Oxford, R. (1990) Language Learning Strategies: What Every Teacher Should Know. New York: Newbury House.

Oxford, R. (2003) Towards a more systematic model of L2 learner autonomy. In D. Palfreyman and R.C. Smith (eds) Learner Autonomy Across Cultures: Language Education Perspectives (pp. 75-91). Basingstoke: Palgrave MacMillan.

Palfreyman, D. (2003) Expanding discourse on learner development: A reply to Anita Wenden. Applied Linguistics 24 (2), 243-248.

Palfreyman, D. (2006) Social context and resources for language learning. System 34 (3), $352-370$

Parks, S. and Raymond, P.M. (2004) Strategy use by non-native English speaking students in an MBA program: Not business as usual. The Modern Language Journal 88 (3), 374-389.

Schack, T. and Schack, E. (2005) In- and outgroup representation in a dynamic society: Hong Kong after 1997. Asian Journal of Social Psychology 8, 123-137.

Sealey, A., and Carter, B. (2004) Applied Linguistics as Social Science. London: Continuum.

Stephens, K. (1997) Cultural stereotyping and intercultural communication: Working with students from the People's Republic of China in the UK. Language and Education 11 (2), 113-124.

Thorne, S. (2005) Epistemology, politics, and ethics in sociocultural theory. The Modern Language Journal 89 (3), 393-409.

Toohey, K. and Norton, B. (2003) Learner autonomy as agency in sociocultural settings. In D. Palfreyman and R.C. Smith (eds) Learner Autonomy Across Cultures: Language Education Perspectives (pp. 58-72). Basingstoke: Palgrave MacMillan. 
Tseng, W., Dornyei, Z. and Schmitt, N. (2006) A new approach to assessing strategic learning: The case of self-regulation in vocabulary acquisition. Applied Linguistics 27 (1), 78-102.

Watson-Gegeo, K.A. (2004) Mind, language, and epistemology. The Modern Language Journal 88 (3), 331-487.

Wenger, E. (1998) Community of Practice: Learning, Meaning, and Identity. New York: Cambridge University Press.

Wenger, E. (2000) Communities of practice and social learning systems. Organization $7(2), 225-246$.

Zhang, J. (2003) Research into Chinese EFL learner strategies: Methods, findings and instructional issues. RELC Journal 34 (3), $284-322$.

Zuengler, J. and Miller, E.R. (2006) Cognitive and sociocultural perspectives: Two parallel SLA worlds. TESOL Quarterly 40 (1), 35-58. 